\title{
Movimentação de Dunas Móveis Transgressivas sobre o Distrito de Itaúnas - Espírito Santo, Sudeste Brasileiro
}

Caíque Lima Cabral, Diego Martins Vellasquez de Oliveira, Willian Cruz Gouvea Junior, Ingrid Rayanne Lima da Silveira, Daniel Fernandes e João Wagner Alencar Castro

Laboratório de Geologia Costeira, Sedimentologia \& Meio Ambiente - LAGECOST, Museu Nacional, Universidade Federal do Rio de Janeiro

Copyright 2021, SBGf - Sociedade Brasileira de Geofísica.

This paper was prepared for presentation during the $17^{\text {th }}$ International Congress of the Brazilian Geophysical Society held in Rio de Janeiro, Brazil, $16-19$ August 2021.

Contents of this paper were reviewed by the Technical Committee of the $17^{\text {th }}$ International Congress of the Brazilian Geophysical Society and do not necessarily represent any position of the SBGf, its officers or members. Electronic reproduction or storage of any part of this paper for commercial purposes without the written consent of the Brazilian Geophysical Society is prohibited.

\section{Resumo}

Itaúnas, distrito do município de Conceição da Barra - Espírito Santo, desde os anos cinquenta, vem passando por intenso processo de movimentação de dunas móveis transgressivas. A dinâmica eólica contemporânea, favorecida pelo desmatamento da vegetação arbórea da atual planície de deflação, acarretou soterramento de cursos d'água, estradas vicinais e praticamente toda antiga vila de pescadores. Objetiva-se estudar a dinâmica eólica local a partir de estimativas de taxas de movimentação das feições eólicas, delimitação de áreas de risco geológico e simulação do regime de ventos locais. Foram utilizadas técnicas de sensoriamento remoto e geoprocessamento, visando estimar taxas de avanço das feições eólicas e definir áreas de maior susceptibilidade geológica. A base de dados climáticos utilizada, inclui informações do Instituto Nacional de Meteorologia, entre 1971 a 2018 e imagens de satélite do Google Earth Pro, correspondentes aos anos 2006, 2010, 2017 e 2020. As imagens foram georreferenciamento através do software ArgGIS 10.3, utilizando o Datum WGS 84 e projeção UTM 24S e o regime de ventos determinado através do software HYSPLIT, versão online. Resultados obtidos sugerem que a maioria das feições eólicas atuais, desenvolveram-se a partir da coalescência de dunas coppice, alimentadas pela planície de deflação atual. Constatou-se que os setores noroeste e sudoeste da área de estudo apresentam maiores taxas de movimentação, acarretando no soterramento parcial de trechos da estrada de acesso a cidade de Pedro Canário, do Rio Itaúnas e da atual área urbana. Tal fato, deve-se a maior quantidade de sedimentos transportados através da pista vento durante os períodos de inverno e verão, proveniente dos quadrantes leste/sudeste e leste/nordeste, respectivamente. Entre 2006 e 2017, registrou-se uma taxa média de movimentação de dunas na ordem de $3,0 \mathrm{~m} /$ ano. Por se tratar de um segmento litorâneo submetido a clima tropical úmido, os resultados apresentaram-se relevantes. Desta forma, o conhecimento quantitativo dos processos de soterramento por dunas móveis transgressivas, possibilita a elaboração de planos e medidas de mitigação para contenção de dunas móveis, minimizando assim, os impactos econômicos, sociais e ambientais negativos sobre essa região do litoral do Brasileiro. 